\title{
What Impact Does COVID-19 Have in Cirrhotics?
}

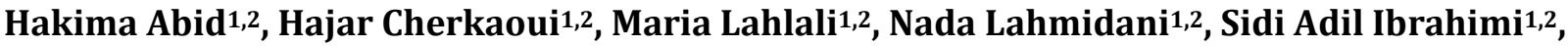 Mohammed El Abkari1,2}

${ }^{1}$ Department of Hepato-gastroenterology, Hassan II University Hospital, Fez, Morocco

${ }^{2}$ Faculty of Medicine and Pharmacy of Fez, University of Sidi Mohammed Ben Abdellah, Fez, Morocco

Email: abidhakima@hotmail.com

How to cite this paper: Abid, H., Cherkaoui, H., Lahlali, M., Lahmidani, N., El Abkari, M. and Ibrahimi, S.A. (2021) What Impact Does COVID-19 Have in Cirrhotics? Open Journal of Gastroenterology, 11, 16-27.

https://doi.org/10.4236/ojgas.2021.111002

Received: November 30, 2020

Accepted: January 26, 2021

Published: January 29, 2021

Copyright $\odot 2021$ by author(s) and Scientific Research Publishing Inc. This work is licensed under the Creative Commons Attribution International License (CC BY 4.0).

http://creativecommons.org/licenses/by/4.0/

\begin{abstract}
SARS-Cov-2 is a novel coronavirus discovered in Wuhan, China in late 2019 and responsible for respiratory distress. Aim: study the impact of COVID-19 among patients with cirrhosis. Patients and methods: We conducted a prospective study for a period of 9 months (April 1st-December 1st) that included cirrhotic patients infected with SARS-Cov-2 followed in the gastroenterology department in the University Hospital Hassan II. Results: Among 1437 patients hospitalised for SARS-Cov-2, 8 cirrhotic patients were included in a period of 9 months (April 1st-December 1st). The mean age is $55 \mathrm{y} / \mathrm{o}$ and most are female $(n=6)$. The aetiology of cirrhosis is mostly HCV $(n=3), H B V(n$ $=2$ ). Half of the infected patients had acute bleeding (one of them had hepatic encephalopathy) and one patient had respiratory distress. Most of the patients had a negative PCR at the end of the hospital stay $(n=5)$. The mortality rate was $25 \%$ and patients were followed up for a period of 4 months. Conclusion: In the studied population, clinical manifestations were essentially a decompensation of cirrhosis.
\end{abstract}

\section{Keywords}

SARS-Cov-2, Cirrhosis, Decompensation, Severity

\section{Introduction}

SARS-Cov-2 (Severe acute respiratory syndrome coronavirus-2) is a new coronavirus that was detected in Wuhan, China in December 2019 [1]. It is responsible for COVID-19 disease with more than 55 million confirmed cases including one million deaths worldwide. In Morocco, this figure rises to 306,993 positive cases including 5061 deaths by November 2020 [1]. 
The SARS-Cov-2 virus is a single-stranded RNA virus of positive polarity, enveloped and belonging to the coronavirus family [2]. It is responsible for dry cough, fever and shortness of breath that can progress to respiratory distress following interstitial pneumonia [3]. It can also be responsible for systemic manifestations following the cytokine storm it can cause [4]. The gateway for the virus is the ACE (angiotensin-converting enzyme) receptors in type 2 alveolar cells, cholangiocytes, enterocytes and myocardial cells [5]. This may explain the multi-systemic involvement due to coronavirus [6] and the more severe forms of the disease in patients with co-morbidities [3].

Cirrhosis of the liver alone is responsible for 1.2 million deaths per year worldwide (3.5\% of global mortality) [7] and cirrhotic patients are at high risk of developing a SARS-Cov-2 infection due to their immune dysfunction [8]. In these patients, the virus is responsible for hepatic damage that alters the liver's ability to synthesize and may lead to severe liver failure [9] and decompensation of cirrhosis [8]. This may explain the high morbidity and mortality rate of cirrhotic patients with COVID-19 [8].

Some studies have focused on the demographic and clinical characteristics of cirrhotic patients with COVID. According to an Asian study, the prevalence of underlying liver disease in patients with COVID-19 is $2 \%-11 \%$ [10] and $3 \%$ according to an Italian study [11]. We conducted a prospective study in our training to determine the characteristics of cirrhotic patients infected with SARS-Cov-2.

\section{Purpose of the Study}

The objective of our study is to determine the demographic, clinical, paraclinical, therapeutic and prognostic characteristics of cirrhotic patients with COVID-19. To determine the impact of COVID-19 on the evolution of underlying liver disease on the one hand and the evolution of SARS-Cov-2 viral infection in this population on the other hand.

\section{Patients and Methods}

\section{- Type and period of study}

This is a prospective case-control study extended over a 9-month period (April-December 2020) at the Hassan II University Hospital in Fez. Cases are COVID-19 cirrhotic patients hospitalized in a COVID+ department and controls are COVID- cirrhotic patients hospitalized in the hepato-gastroenterology department during the study period.

\section{- Patient selection criteria}

o Inclusion criteria: Patients included in our study are treated at the Hassan II University Hospital of Fez. They are all over 18 years of age, with chronic liver disease at the cirrhosis stage, and have all agreed to participate in our study. Cases have SARS-Cov-2 infection, confirmed by positive RT-PCR or typical CT scan findings are hospitalized in a COVID+ facility. Controls are hospitalized in the HGE department, have chronic liver disease and are 
COVID-.

o Exclusion criteria: Patients excluded are non-cirrhotic patients under 18 years of age, non-cirrhotic, COVID-19 negative and not hospitalized in the Hassan II UHC.

\section{- Study population}

For patients meeting the inclusion criteria, we have defined the following parameters:

o Cirrhotic patients: patients whose clinical, endoscopic and radiological characteristics are suggestive of chronic liver disease and portal hypertension or who are undergoing follow-up consultation for cirrhosis.

o Severe hepatic insufficiency: Hepatic insufficiency occurring in cirrhotic patients which may be clinically manifested by jaundice, coagulopathy and complicated by the occurrence of ascites, hepatic encephalopathy or digestive hemorrhage.

o Acute decompensation of cirrhosis: defined by the recent occurrence of ascites, hepatic encephalopathy, GI bleeding, an infectious episode or any combination of these criteria.

The severity of the SARS-Cov-2 infection is defined by the following criteria:

o Asymptomatic: Patients are asymptomatic, a PCR has been performed following recent contact or travel to an area of high virus circulation.

o Moderate: patients have fever, cough, asthenia, or other non-specific symptoms.

o Severe: Patients maintain saturation $<93 \%$ despite high-flow oxygen therapy, or respiratory rate $>30$ per minute, or patients have ARDS (acute respiratory distress syndrome).

\section{- Epidemiological data collection}

Epidemiological, clinical, paraclinical and therapeutic data were collected from patients meeting the criteria for inclusion on an operating sheet from medical records and the Hosix computer system. These data include patients' symptoms, medication intake, consumption of alcohol or other hepatotoxic foods, presentation of the disease, results of biological and radiological assessments performed during hospitalization, and treatments received. Hepatic function was evaluated by clinical (presence of ascites, digestive hemorrhage, hepatic encephalopathy) and biochemical (platelet levels, TP, INR, transaminases, bilirubin, albumin) criteria. Child and MELD scores were calculated before and after the SARS-Cov-2 infection. Our primary objective was to determine the clinical and prognostic characteristics of cirrhotic patients with SARS-Cov-2 infection, our secondary objective is to determine the impact of the new coronavirus on the decompensation of cirrhosis in this population.

\section{- Comparative study}

In order to determine the impact of COVID-19 on the evolution of cirrhotic patients we have:

o Gathered the data of the last consultation of the cases before they were reached by the COVID-19 in order to study the evolution of their clinical and 
paraclinical parameters.

o Gathered a control population composed of cirrhotic patients not affected by COVID-19, hospitalized in our department in the same period of the study. The aim is to compare the evolution of the two populations of cirrhotic patients (COVID+ and COVID-).

\section{- Statistical analysis}

The data collected is entered into Excel. Descriptive statistical analysis was used. Quantitative values were reported as mean, median and standard deviation. We used the statistical test $\chi^{2}$ or the Fisher statistical test with a significance level of 0.05 for qualitative values. The software used is SPSS.

\section{Results}

\section{- Demographic and clinical characteristics of patients}

Between April 1st and December 1st, 2020, 8 cirrhotic patients were admitted to the COVID+ facilities of the Hassan II University Hospital of Fez for management of an SARS-Cov-2 infection out of a total of 1437 patients, i.e. a prevalence of $0.5 \%$. All these patients benefit from regular follow-up in the hepato-gastro-enterology department of the Hassan II University Hospital of Fez for management of their underlying liver disease.

The mean age of the patients was $55.5 \pm 8.2$ years ( $47-71$ years, median: 54$)$, with a clear predominance of females $(n=6$ patients, $\mathrm{p}=0.012)$, two patients were diabetic ( $\mathrm{n}=2, \mathrm{p}=0.52$ ). Two patients had controlled hypertension under treatment. Two patients $(n=2)$ had a history of cervicotomy type surgery. Cirrhosis was post viral $C$ in 3 cases $(n=3, p=0.13$ ) (one patient still on sofosbuvir + daclatasvir, one treated and cured and one untreated), post viral B in two patients ( $\mathrm{n}=$ $2, \mathrm{p}=0.27$ ), including one patient on Tenofovir, one patient on entecavir), due to steatohepatitis in 2 patients $(\mathrm{n}=2, \mathrm{p}=0.34)$, and of undetermined origin in one patient ( $\mathrm{n}=1, \mathrm{p}=0.12$ ). None of the patients has cirrhosis of alcoholic origin.

Eleven patients form the control group, the mean age was $55 \pm 18$ years (2980, median: 58$)$, with a predominance of females $(n=8)$, two patients were diabetic $(n=2)$. Cirrhosis was post viral $C(n=1)$, autoimmune $(n=2), \operatorname{PBC}(n=$ $2)$, steatohepatitis $(n=1)$, and of undetermined origin $(n=5)$.

Prior to infection with SARS-Cov-2, half of the patients $(\mathrm{n}=4, \mathrm{p}=0.8)$ had compensated cirrhosis (Child A) and the other half $(n=4)$ had decompensated cirrhosis on diuretics and beta-blockers (Child B-C). All patients with decompensated cirrhosis have a history of hemorrhagic and ascitic decompensation (n $=4, \mathrm{p}=0.8$ ) treated with beta-blockers and diuretics, of which 2 patients have a history of hepatic encephalopathy $(n=2, p=0.33)$ and one patient with HCC under chemoembolization protocol $(\mathrm{n}=1, \mathrm{p}=0.63)$. The mean MELD was $12 \pm$ 6.8 (6 - 25, Median 11). Half of the patients $(n=4)$ had community-acquired SARS-Cov-2 infection and half $(n=4)$ had nosocomial infection.

In patients with hemorrhagic decompensation $(n=4)$, all patients were on beta-blockers for secondary prevention and three patients were on ligation protocol. Two patients missed their ligation session due to the impact of SARS-Cov-2 
on the endoscopic activity of the department.

In the control group, one third of the patients had a history of ascitic decompensation, three patients had a history of hemorrhagic decompensation, three patients had a history of HCC (one patient on chemoembolization protocol and two patients on Sorafenib) and one patient had a history of H.E. The various sociodemographic and clinical characteristics are summarized in Table 1.

At the time of infection with SARS-Cov-2, half had a fever $(n=4)$, three patients had a dry cough $(n=3)$, two patients had pharyngitis $(n=2)$, the majority had asthenia $(n=5)$, and two patients were asymptomatic $(n=2)$. One patient presented respiratory distress. The positive diagnosis was made by RT-PCR in the majority of patients $(n=5)$ and chest CT scan $(n=3)$. Respiratory manifestations are summarized in Figure 1 . Clinically, the majority of patients $(n=7)$ had ambient air saturation greater than $93 \%$, correct blood pressure, and normal cardio-thoracic auscultation. One patient presented with respiratory distress with $70 \%$ room air saturation on oxygen therapy initially without improvement and then on NIV. Thoracic CT scan showed lesions suggestive of SARS-Cov-2 with $70 \%$ lung involvement.

Table 1. Sociodemographic and clinical characteristics of patients.

\begin{tabular}{|c|c|c|c|}
\hline & Cirrhotics COVID+ & Cirrhotics COVID- & $\mathrm{p}$ value \\
\hline Number of patients & $\mathrm{n}=8$ & $\mathrm{n}=11$ & \\
\hline Age & 55.5 & 55 & - \\
\hline Gender $(\mathrm{F} / \mathrm{M})$ & $\mathrm{n}=6$ & $\mathrm{n}=8$ & $\mathrm{p}=0.012$ \\
\hline Smoking & $\mathrm{n}=2$ & $\mathrm{n}=1$ & $\mathrm{p}=0.34$ \\
\hline Diabetes & $\mathrm{n}=2$ & $\mathrm{n}=4$ & $\mathrm{p}=0.52$ \\
\hline Hyperaterial tension & $\mathrm{n}=2$ & $\mathrm{n}=0$ & $\mathrm{p}=0.27$ \\
\hline surgical history & $\mathrm{n}=2$ & $\mathrm{n}=0$ & $\mathrm{p}=0.27$ \\
\hline Viral infection C & $\mathrm{n}=3$ & $\mathrm{n}=1$ & $\mathrm{p}=0.13$ \\
\hline Viral infection B & $\mathrm{n}=2$ & 0 & $\mathrm{p}=0.27$ \\
\hline Steatohepatitis & $\mathrm{n}=2$ & $\mathrm{n}=1$ & $\mathrm{p}=0.34$ \\
\hline Autoimmune & 0 & $\mathrm{n}=2$ & - \\
\hline $\mathrm{PBC}$ & 0 & $\mathrm{n}=1$ & - \\
\hline Undetermined & $\mathrm{n}=1$ & $\mathrm{n}=5$ & $\mathrm{p}=0.12$ \\
\hline \multicolumn{4}{|l|}{ Cirrhosis } \\
\hline o Compensated (Child A) & $\mathrm{n}=4$ & $\mathrm{n}=3$ & \multirow{2}{*}{$\mathrm{p}=0.8$} \\
\hline o Décompensated (Child B-C) & $\mathrm{n}=4$ & $\mathrm{n}=8$ & \\
\hline hemorrhage decompensation history & $\mathrm{n}=4$ & $\mathrm{n}=3$ & $\mathrm{p}=0.8$ \\
\hline hepatic encephalopathy history & $\mathrm{n}=2$ & $\mathrm{n}=1$ & $\mathrm{p}=0.33$ \\
\hline HCC history & $\mathrm{n}=1$ & $\mathrm{n}=3$ & $\mathrm{p}=0.63$ \\
\hline ascitic decompensation history & $\mathrm{n}=4$ & $\mathrm{n}=4$ & $\mathrm{p}=0.8$ \\
\hline Mean MELD & 12 & 9 & \\
\hline
\end{tabular}

PBC: Primary biliary cirrhosis, MELD: model for end stage liver disease, H.E: Hepatic encéphalopathy, HCC: Hepatocellular carcinoma. 


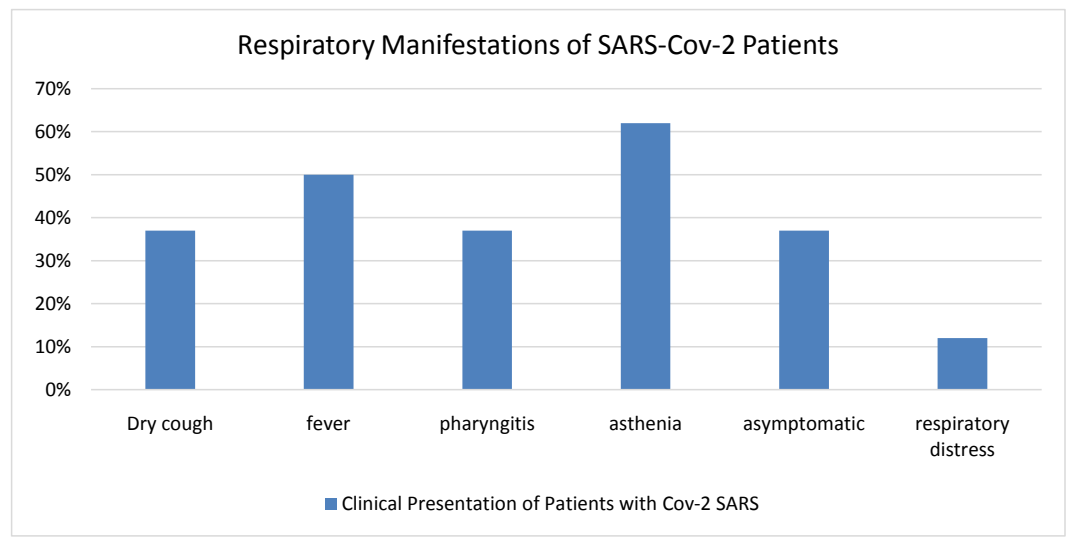

Figure 1. Respiratory manifestations of cirrhotic patients with SARS-Cov-2.

In terms of chronic hepatopathy, $50 \%$ of the patients showed hemorrhagic decompensation $(\mathrm{n}=4, \mathrm{p}=0.038)$ of their concomitant cirrhosis at the time of their SARS-Cov-2 infection. HCC was incidentally discovered at the time of coronavirus infection in two patients $(\mathrm{n}=2, \mathrm{p}=0.89$ one of whom had ruptured HCC that required embolization) making the number of HCC patients in our series of 3. No patient had ascitic decompensation (Figure 2). Half of the patients maintained a Child A score $(\mathrm{n}=4, \mathrm{p}=0.027)$ and the other half had a worsening of their CHILD score. The mean MELD was $12 \pm 7.2$ (6 - 25, median 9.5).

\section{- Paraclinical characteristics}

Prior to the SARS-Cov-2 infection, patients had a mean hemoglobin of $10 \pm$ $2.7 \mathrm{~g} / \mathrm{dl}$ (7.1 - $13.5 \mathrm{~g} / \mathrm{L}$, median: 9.55), a mean PT of $72 \% \pm 27 \%$ (39\% - 100\%, median: $77 \%)$ and 3 patients had thrombocytopenia $(70,000 / \mu \mathrm{L}, 81,000 / \mu \mathrm{L}$, and $46,000 / \mu \mathrm{L}$ respectively). Transaminases were normal in all patients with a mean AST of 33.4 IU/L and ALT of 14.6 IU/L. Patients had a mean albumin of $37 \pm$ $5.27 \mathrm{~g} / \mathrm{L}(25$ - $41 \mathrm{~g} / \mathrm{L})$. Mean bilirubin was $16.57 \pm 19.45 \mathrm{mg} / \mathrm{L}$ (5 - $64 \mathrm{mg} / \mathrm{L}$, median $10.5 \mathrm{mg} / \mathrm{L}$ ). Renal function (urea and creatinine) was normal. Liver ultrasound was performed in all patients. It showed a heterogeneous liver with irregular contours in all patients, a steatosis liver in 2 patients $(n=2)$, a lesion suggestive of HCC in 1 patient. The mean MELD was $12 \pm 6.8$ (6 - 25, Median 11).

After infection with SARS-Cov-2, the mean hemoglobin was $8.87 \pm 2.57 \mathrm{~g} / \mathrm{dl}$ (4.6 - 13, median 8.6) and 2 patients received a red blood cell transfusion. This lower hemoglobin level may be explained by the hemorrhagic decompensation that occurred in $50 \%$ of patients. None of the patients had hyperleukocytosis (mean white blood cell count of 4460 cells $/ \mu \mathrm{L}$ ) and a mean CRP of $24 \pm 26 \mathrm{mg} / \mathrm{L}$ (0 - 64, median: 8). A worsening of platelet levels was noted in the 3 thrombocytopenic patients $(34,000 / \mu \mathrm{L}, 53,000 / \mu \mathrm{L}$ and 32,000 respectively), and the mean PT was $75 \% \pm 28 \%(25 \%-100 \%$, median: 81$)$. Transaminases remained normal (mean ASAT of $35 \mathrm{IU} / \mathrm{L}$ and ALAT of $18 \mathrm{IU} / \mathrm{L}$ ). Patients maintained stable albumin levels (34 $\pm 5.35 \mathrm{~g} / \mathrm{dl}, 25-39 \mathrm{~g} / \mathrm{dl})$, bilirubin $(18 \pm 20 \mathrm{mg} / \mathrm{l}, 6-70 \mathrm{mg} / \mathrm{l}$, median: $11.4 \mathrm{mg} / \mathrm{l}$ ). Renal function (urea and creatinine) remained normal in all patients. The mean MELD remained stable $12 \pm 7.2$ (6 - 25, median 9.5). These characteristics are summarized in Table 2. 


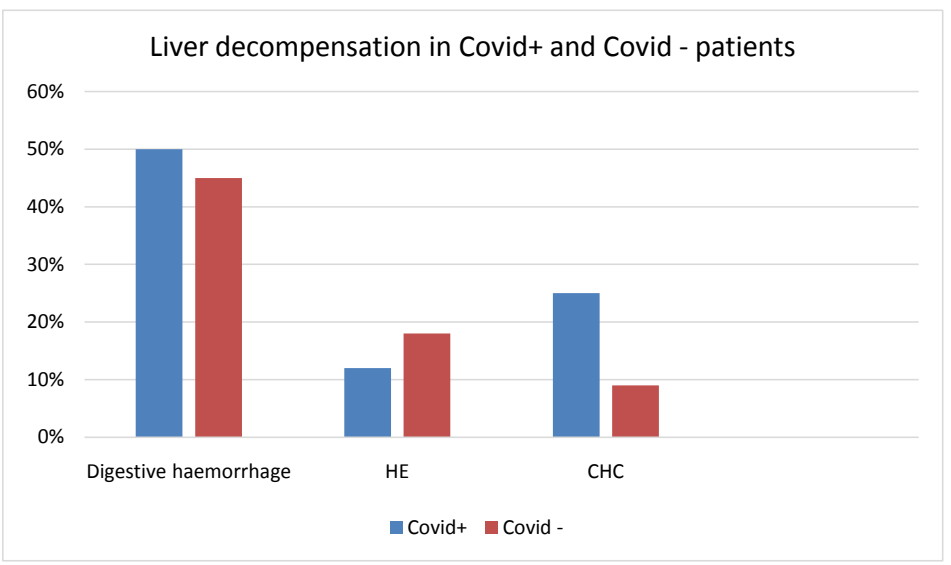

Figure 2. Decompensation of cirrhosis at the time of the study in COVID+ and COVID- patients.

Table 2. Table showing changes in biological parameters of COVID+ cirrhotic patients before and after their infection with SARS-Cov-2.

\begin{tabular}{ccc}
\hline & Before SARS-Cov- 2 infection & After SARS-Cov-2 infection \\
\hline Hemoglobin & $10 \pm 2.7 \mathrm{~g} / \mathrm{dl}(7.1-13.5 \mathrm{~g} / \mathrm{L})$ & $8.87 \pm 2.57 \mathrm{~g} / \mathrm{dl}(4.6-13)$ \\
PT & $72 \% \pm 27 \%(39 \%-100 \%)$ & $75 \% \pm 28 \%(74 \%-100 \%)$ \\
Albumin & $37 \pm 5.27 \mathrm{~g} / \mathrm{l}(25-41 \mathrm{~g} / \mathrm{L})$ & $34 \pm 5.35 \mathrm{~g} / \mathrm{dl}(25-39 \mathrm{~g} / \mathrm{dl})$ \\
Bilirubin & $16.57 \pm 19 \mathrm{mg} / \mathrm{l}(5-64 \mathrm{mg} / \mathrm{l})$ & $18 \pm 20 \mathrm{mg} / \mathrm{l}(6-70 \mathrm{mg} / \mathrm{l})$ \\
MELD & $12 \pm 6.8(6-25)$ & $12 \pm 7.2(6-25)$ \\
\hline
\end{tabular}

\section{- Patient management}

In patients with hemorrhagic decompensation $(\mathrm{n}=4)$, all patients received a octreotide perfusion and 2 patients received a blood transfusion (baseline $\mathrm{Hb}$ of $4.5 \mathrm{~g} / \mathrm{dl}$ and $6 \mathrm{~g} / \mathrm{dl}$ respectively). An EGD was performed in 3 patients. It showed 3 varicose veins (VV) with 2 stage II and 1 stage I ligated in the 1st patient, 4 stage I VV with portal hypertension gastropathy (patient under ligation protocol) in the 2nd patient, 4 stage III VV with red spots ligated in the 3rd patient. The 4th patient did not benefit from EGD during her hospitalization, she was scheduled for consultation during her follow-up after PCR negativation since she presented a low abundance hematemesis with a hemoglobin of $10 \mathrm{~g} / \mathrm{L}$, she did not relapse during hospitalization.

Abdominal imaging was performed in 3 patients with hemorrhagic decompensation. An abdominal angioscan revealed a thrombosis of the portal vein and suprahepatic vein, of the splenic vein with a fusiform aneurysm thrombosed of the splenic vein in the 1st patient who was put under curative anticoagulation. In the 2nd patient, an abdominal ultrasound showed a $4 \mathrm{~cm}$ segment IV lesion suggestive of HCC. In the 3rd patient, an abdominal angioscan showed a ruptured HCC, with significant extravasation of the contrast agent. The patient benefited from hepatic artery embolization.

The SARS-Cov-2 pandemic had a major impact on the department's ambula- 
tory activity. Among the patients admitted for hemorrhagic decompensation, 2 patients did not benefit from HCC screening ultrasound and the diagnosis was made at the time of their SARS-Cov-2 infection. Another patient missed her HCC chemoembolization session, and one patient did not benefit from her ligation session and experienced hemorrhagic decompensation.

In our series, the majority of patients received the hydroxychloroquine/azithromycin protocol $(n=5)$ and three patients received only symptomatic treatment (advanced cirrhosis Child B-C). We noted no side effects in patients treated with hydroxychloroquine/azithromycin (no digestive disturbances (nausea or vomiting), transaminase elevation or QT prolongation). None of the patients received antiviral therapy (lopinavir + ritonavir, tocilizumab, remdesivir, oseltamivir, favipavir). This can be explained by the non-severe forms of SARS infection that almost all patients in our series presented. All patients were put on anticoagulation. It is preventive in most cases and curative in two cases (the patient with trunk thrombosis and the patient with respiratory distress). We did not note any hemorrhagic side effects in our series.

\section{- Prognosis}

The average length of hospitalization is 10 days, during which the majority of patients received the hydroxychloroquine/azithromycin protocol. The control PCR was performed on day 10 in all patients, returning negative in five patients $(\mathrm{n}=5, \mathrm{p}=0.18)$ and positive in three patients $(\mathrm{n}=3)$. Containment for 7 days was indicated in all patients. The average follow-up duration of our study is 4 months, with a mortality rate at the end of 4 months of $25 \%$, hence the impact on the mortality of the COVID in cirrhotic patients. As a conclusion in our series, 4 patients presented a hemorrhagic decompensation, one of which presented a hepatic encephalopathy. HCC was found in 2 patients. No patient presented ascitic decompensation. Respirationally, one patient presented with severe respiratory distress. There were two deaths in our series (the patient who presented with respiratory distress and the patient who presented with hemorrhagic decompensation with hepatic encephalopathy). The average follow-up time in our study was 4 months.

\section{Discussion}

\section{- Demographic characteristics of the study population}

In our 9-month study (April 1st and December 1st, 2020), we included 8 cirrhotic patients, the mean age was 55 years with a clear predominance of females. An Italian study carried out in 9 hospitals in Lombardy by Lavarone and Col. included 50 patients with an average age of 67 years and a clear male predominance (SR F/W: 30\%) [8]. Another meta-analysis carried out in 13 Asian countries by Sarin, et al. included 43 cirrhotic patients with an average age of 43 years and a clear female predominance of $75 \%$ [12]. In our study, $25 \%$ of the patients were diabetic compared to $36 \%$ in the Italian study [8] and $42 \%$ in the Asian meta-analysis $(\mathrm{p}=0.49)$ [12]. In our study, two patients had arterial hypertension (25\%), compared to $58 \%$ according to Lavarone, et al. and $21 \%(\mathrm{p}=0.84)$ 
according to Sarin, et al. [8] [12]. The etiology of cirrhosis was post viral C (37\%), post viral B (37\%), secondary to steatohepatitis (25\%), of undetermined origin (12\%) in our series. According to the Italian study, cirrhosis was essentially post-viral C (28\%), alcoholic (24\%), post-viral B (10\%), steatohepatitis (6\%) [8]. In the Asian series, the etiology of cirrhosis was essentially post-viral $(60 \%, \mathrm{p}=0.003)$, steatohepatitis $(32 \%, \mathrm{p}=0.003)$, alcoholic in $4.6 \%$ [12]. There is a significant association between steatohepatitis and SARS-Cov-2 infection in the cirrhotic patient in the Asian meta-analysis [12]. This could be explained by the high prevalence of diabetes and metabolic syndrome, which are known risk factors for SARS infection [13] (Table 3). We did not show this association in our study, this could be explained by the low number of patients.

\section{- Clinical features}

In our series, $50 \%$ of the patients presented a histiry of cirrhosis decompensation prior to coronavirus infection, a result similar to that of Sarin, in whom $41 \%$ of the patients had a history of cirrhosis decompensation [12]. HCC was present in $12 \%$ of the patients, a result consistent with the literature [8]. The SARS-Cov-2 infection was nosocomial in 1 out of 2 cases, which is consistent with the results of Lavarone, et al. with a nosocomial infection rate of $40 \%$ [8]. In our series, the rate of patients with compensated cirrhosis is (50\%), which is in line with the results of Sarin (59\%) [12] and Lavarone (58\%) [8]. However, according to the literature, patients with a history of decompensated cirrhosis presented an acute decompensation of their cirrhosis during their hospitalization for coronavirus infection with a respective rate of $62 \%$ and $83 \%$ [8] [12], which is similar to the rate found in our series of $75 \%$.

In our study, decompensation was predominantly hemorrhagic, one patient presented with hepatic encephalopathy and no patient presented with ascitic decompensation. In the Asian meta-analysis, patients admitted presented mainly ascitic decompensation $(35.7 \%, \mathrm{p}=0.02)$, hepatic encephalopathy $(21.7 \% \mathrm{p}=$ $0.03)$, and digestive bleeding $(21.7 \%, \mathrm{p}=0.05)$ [12]. According to Lavarone and Col. decompensation was essentially ascitic $(38 \%, \mathrm{p}=0.0621)$ and hepatic encephalopathy $(38 \%, \mathrm{p}=0.025)$.

Table 3. Comparison of epidemiological parameters in our study and in the literature.

\begin{tabular}{cccc}
\hline & Our study & Lavarone and col. [8] & Sarin and col. [12] \\
\hline Number of patients & $\mathrm{n}=9$ & $\mathrm{n}=50$ & $\mathrm{n}=43$ \\
Age & 55 ans & 67 ans & 43 ans, $\mathrm{p}=0.15$ \\
Gender (F/M) & $75 \%, \mathrm{p}=0.012$ & $30 \%$ & $75 \%, \mathrm{p}=0.01$ \\
Diabetes & $25 \%, \mathrm{p}=0.52$ & $36 \%$ & $42 \%, \mathrm{p}=0.49$ \\
arterial hypertension & $25 \%, \mathrm{p}=0.52$ & $58 \%$ & $21 \%, \mathrm{p}=0.81$ \\
Post viral (B+C) & $63 \%, \mathrm{p}=0.02$ & $38 \%$ & $60 \%, \mathrm{p}=0.003$ \\
Steatohepatitis & $25 \%, \mathrm{p}=0.34$ & $6 \%$ & $32 \%, \mathrm{p}=0.003$ \\
Alcoholic & $0 \%$ & $24 \%$ & $4.6 \%, \mathrm{p}=0.45$ \\
Undetermined & $12 \%, \mathrm{p}=0.12$ & $4 \%$ & $2.3 \%$
\end{tabular}


Thus in our series, COVID+ patients presented essentially decompensation of the underlying cirrhosis, encountered in $50 \%$ of the patients, hence the severity of COVID disease in cirrhotic patients in our series. The majority of patients had a moderate form of the infection, one patient experienced respiratory distress and two patients were asymptomatic. Almost all patients had saturation greater than 93 at $\mathrm{AA}$, and one patient required respiratory assistance (oxygen goggles, NIV). This finding appears inconsistent with that reported by Lavarone and Col. (64\% required NIV and 4\% received TI) [8] and Sarin, et al. (42\% of patients required ventilatory support, $\mathrm{p}=0.001)$. This could be explained by the small number of patients included in our study.

\section{- Paraclinical characteristics}

In our series, the mean hemoglobin was $8.7 \mathrm{~g} / \mathrm{dl}$, the white blood cell count was normal and the mean CRP was 24. Thrombocytopenia was noted in 3 patients, PT was correct (75\%), with liver function and renal function remaining normal. A worsening of the Child score was noted in 3 patients (who initially had Child B and C), however in patients with an initial Child A, the Child score remained stable. The MELD remained stable 12 . According to the study by Sarin, et al. the hemoglobin level was $13.5 \mathrm{~g} / \mathrm{dl}$ (only $24 \%$ of patients had a digestive hemorrhage) with normal liver function and normal kidney function [12]. According to Lavarone and Col. 33\% of patients are classified as Child C after coronavirus infection compared to $12 \%$ before the start of the pandemic [8]. This rate is higher in our series with a $50 \%$ worsening of the child's outcome compared to the initial child.

\section{- Treatment}

In our series, $50 \%$ of the patients presented hemorrhagic decompensation and all benefited from sandostatin perfusion, 3 patients benefited from endoscopy, 2 of which benefited from ligation. All patients were placed on anticoagulation. One patient received respiratory assistance. The majority of patients were put on hydroxychloroquine/azithromycin and anticoagulation without any noted complications. In the Italian study, $18 \%$ of patients received hydroxychloroquine alone, $6 \%$ received antiviral therapy (lopinavir, ritonavir) and $28 \%$ of patients received hydroxychloroquine plus antiviral therapy [8]. This difference in treatment strategy can be explained by the severe respiratory manifestations of the patients included in the Italian study.

\section{- Prognosis}

The average length of hospitalization is 10 days in our series, it is 20 days in the Sarin series [12]. The mortality rate in our series is $25 \%$, which is consistent with Sarin, et al. who reported a mortality rate of 34\% [8]. The mean age of the deceased patients in our series is 65 years, which is consistent with the literature [8]. The main etiology of death was severe respiratory manifestations that required ventilatory assistance, followed by decompensated cirrhosis (29\%), 18\% of the deceased patients had decompensated cirrhosis (Child B-C) [8]. This finding is consistent with that of our study where mortality was observed in patients with advanced cirrhosis (Child B-C) and a 25\% mortality rate occurred af- 
ter an average of 10 days from diagnosis. This is consistent with the literature [8]. The average follow-up time for patients in our series is 4 months.

\section{Conclusion}

Our study is a preliminary prospective study on the characteristics of cirrhotic patients with COVID-19 at the Fez University Hospital. It is to our knowledge the first study of its kind in Morocco. In our series, the manifestation of COVID-19 was a decompensation of cirrhosis in half of the cases. However, given the small number of patients included, this finding remains preliminary. It is nevertheless important to note that half of the SARS-Cov- 2 infections in our series are nosocomial, hence the interest of teleconsultation to ensure follow-up of patients with compensated cirrhosis, and to respect barrier measures, hand hygiene and the wearing of masks if hospitalization is required in an emergency.

\section{Conflicts of Interest}

The authors declare no conflicts of interest regarding the publication of this paper.

\section{References}

[1] Coronavirus Update (Live): 34,870,902 Cases and 1,033,970 Deaths from COVID-19 Virus Pandemic-Worldometer. $(03,2020)$ https://www.worldometers.info/coronavirus/

[2] Lu, R., et al. (2020) Genomic Characterisation and Epidemiology of 2019 Novel Coronavirus: Implications for Virus Origins and Receptor Binding. The Lancet, $395,565-574$.

[3] Guan, W.-J., et al. (2020) Clinical Characteristics of Coronavirus Disease 2019 in China. The New England Journal of Medicine, 382, 1708-1720. https://doi.org/10.1056/NEJMoa2002032

[4] Yang, X., et al. (2020) Clinical Course and Outcomes of Critically Ill Patients with SARS-CoV-2 Pneumonia in Wuhan, China: A Single-Centered, Retrospective, Observational Study. The Lancet Respiratory Medicine, 8, 475-481. https://doi.org/10.1016/S2213-2600(20)30079-5

[5] Liu, X., et al. (2020) Composition and Divergence of Coronavirus Spike Proteins and Host ACE2 Receptors Predict Potential Intermediate Hosts of SARS-CoV-2. Journal of Medical Virology, 92, 595-601. https://doi.org/10.1002/jmv.25726 https://pubmed.ncbi.nlm.nih.gov/32100877/

[6] Xu, H., et al. (2020) High Expression of ACE2 Receptor of 2019-nCoV on the Epithelial Cells of Oral Mucosa. International Journal of Oral Science, 12, 8. https://doi.org/10.1038/s41368-020-0074-x

[7] Moon, A.M., Singal, A.G. and Tapper, E.B. (2019) Contemporary Epidemiology of Chronic Liver Disease and Cirrhosis. Clinical Gastroenterology and Hepatology, 18, 2650-2666. https://doi.org/10.1016/j.cgh.2019.07.060

[8] Iavarone, M., et al. (2020) High Rates of 30-Day Mortality in Patients with Cirrhosis and COVID-19. Journal of Hepatology, 73, 1063-1071.

https://doi.org/10.1016/j.jhep.2020.06.001

https://www.sciencedirect.com/science/article/pii/S0168827820303652 
[9] Sarin, S.K., et al. (2009) Acute-on-Chronic Liver Failure: Consensus Recommendations of the Asian Pacific Association for the Study of the Liver (APASL). Hepatology International, 3, 269-282. https://doi.org/10.1007/s12072-008-9106-X

[10] Huang, C., et al. (2020) Clinical Features of Patients Infected with 2019 Novel Coronavirus in Wuhan, China. The Lancet, 395, 497-506. https://doi.org/10.1016/S0140-6736(20)30183-5

[11] Grasselli, G., et al. (2020) Baseline Characteristics and Outcomes of 1591 Patients Infected With SARS-CoV-2 Admitted to ICUs of the Lombardy Region, Italy. JAMA, 323, 1574-1581. https://doi.org/10.1001/jama.2020.5394

[12] Sarin, S.K., et al. (2020) Pre-Existing Liver Disease is Associated with Poor Outcome in Patients with SARS CoV2 Infection; The APCOLIS Study (APASL COVID-19 Liver Injury Spectrum Study). Hepatology International, 14, 690-700. https://doi.org/10.1007/s12072-020-10072-8

[13] Boettler, T., et al. (2020) Impact of COVID-19 on the Care of Patients with Liver Disease: EASL-ESCMID Position Paper after 6 Months of the Pandemic. JHEP Reports. Innovation in Hepatology, 2, Article ID: 100169. https://doi.org/10.1016/j.jhepr.2020.100169

\section{Abreviations}

AA: Ambient Air

ACE: Angiotensin converting enzyme

ALAT: Alanine transaminase

ASAT: Aspartate aminiotransminase

COVID-19: Coronavirus disease 2019

CRP: C Reactive Protein

EGD: Esophagogastroduodenoscopy

GI: Gastrointestinal

Hb: Hemoglobin

HCC: Hepatocellular carcinoma

HGE: Hepato-gastroenterology

HE: Hepatic encephalopathy

INR: International normalized ratio

MELD: Model for end liver disease

NIV: Non invasive ventilation

PBC: Primary biliary cholangitis

PH: Portal Hypertension

PT: Prothrombin Time

RNA: Ribonucleic acid

RDS: Respiratory Distress Syndrome

RT-PCR: Reverse transcriptase polymerase chain reaction

SARS-CoV-2: Severe acute respiratory syndrome-Coronavirus 2

SR: Sex-Ratio

TI: Tracheal intubation

UHC: University hospital complex

VV: Varicose veins 